\title{
Detachment of soil organic carbon by rainfall splash: experimental assessment on three agricultural soils of Spain
}

\author{
Santiago Beguería* \\ Estación Experimental de Aula Dei (EEAD-CSIC), 1005 Avda. Montañana, Zaragoza, \\ Spain \\ Marta Angulo-Martínez \\ Department of Civil and Environmental Engineering, Pratt School for Engineering, Duke \\ University, Durham, NC \\ Leticia Gaspar \\ Environmental Science Program, University of Northern British Columbia, 3333 \\ University Way, Prince George, British Columbia, V2N 4Z9, Canada \\ Ana Navas \\ Estación Experimental de Aula Dei (EEAD-CSIC), 1005 Avda. Montañana, Zaragoza, \\ Spain
}

\begin{abstract}
An experiment was undertaken to measure the concentration of soil organic carbon (SOC) in particles mobilized by rainfall splash under natural precipitation and to assess its relationship with soil and precipitation properties. Splash cups were deployed on three agricultural soils typical of the central Ebro Valley in Spain (a Cambisol, a Gypsisol, and a Solonchak), and the rainfall characteristics (intensity, kinetic energy) were measured by means of
\end{abstract}

\footnotetext{
${ }^{*}$ Corresponding author

Email address: santiago.begueria@csic.es (Santiago Beguería)
} 
a disdrometer (optical spectro-pluviometer). Evidences of SOC enrichment, i.e. a significantly higher concentration in the splashed material with respect to the parent material, were found in the three soils under study. Differences were found, too, between two particle size fractions (less than $0.05 \mathrm{~mm}$ and between 0.05 and $0.5 \mathrm{~mm}$ ), with higher SOC enrichment in the coarsest fraction. While the amount of splash was clearly related to the erosivity of each rainfall event, no significant effect was found with respect to the SOC concentration. Between the three soils, the Gypsisol exhibited the highest rates of SOC enrichment, and also the largest difference between size fractions. Splash plays an important role on mobilizing fresh carbon fractions, and under certain conditions it may interrupt the soil carbon cycling by favoring the removal of SOC by other erosive processes such as runoff wash, thus preventing its incorporation into the soil carbon pool.

Keywords: Splash erosion, Soil Organic Carbon, Rainfall Erosivity, Particle Fractions, Cambisol, Solonchak, Gypsisol

\section{Introduction}

The soil organic carbon (SOC) is a heterogeneous mixture of organic com3 ponents such as plant, animal and microbial residues in different stages of 4 decomposition (Post and Kwon, 2000), being the major component of organic matter in the soils. The SOC improves the aggregation, permeability and water-holding capacity of the soils, having a large influence on soil quality and fertility. As such, the content of SOC in soils is normally used as a main indicator of soil quality (Sinoga et al., 2012). SOC also has a great capacity for storage and exchange with atmospheric $\mathrm{CO}_{2}$ through plant photosynthe- 
sis, thus having an important role on the global carbon cycle. Therefore, to preserve the quality of the soils it is necessary to maintain a neutral or positive balance between the input of SOC by the addition of litter and dead animal material, and SOC loss by mineralization or by physical removal (erosion) (Lal et al., 2004).

At the field scale, large spatial differences in SOC content can exist due to soil erosion and redistribution processes. Recent studies examined the relationships between the patterns of SOC and soil redistribution processes using fallout ${ }^{137} \mathrm{Cs}$, demonstrating a very good relationship between SOC loss/gain ratios and soil erosion rates (Ritchie et al., 2007; Navas et al., 2012). In many natural and agricultural landscapes water erosion is the main agent redistributing SOC (Jacinthe et al., 2004), and apart from mineralization, the depletion of SOC in agricultural soils has been related to the degree of soil erosion (Lal, 2005; Li et al., 2006). The loss of organic carbon compounds as a result of water erosion reduces soil aggregation and stability, further intensifying the efficacy of erosive processes in a positive feedback that may ultimately lead to the loss of soil fertility and to desertification.

Water erosion is a complex process involving several other processes. Splash, that is the detachment of soil particles and their transportation caused by raindrop impacts, can be considered a first stage in the process of soil particle detachment and transport (Quansah, 1981). Raindrop impacts occur everywhere, and may come from natural precipitation as well as from overhead irrigation. The energy of raindrops impacting the soil surface during a rain or irrigation event is able to detach soil particles and even to break some soil aggregates. The displacement of splashed particles occurs in all 
directions, but if the soil is not totally flat it results in a preferential movement of soil particles in the direction of the slope. Perhaps most importantly, the splashed particles are more vulnerable to experience further erosion by rain wash. Depending on the topographical conditions the displacement of soil particles can be more influenced by splash than by runoff (Rose, 1960 ; Hairsine and Rose, 1991). Meyer and Wischmeier (1969) indicated that the capacity of rainfall to transport soil by splash depends on factors such as the slope gradient, the amount and intensity of rainfall, the soil properties and other factors such as the micro-topography and the wind velocity during the rainfall event. Mati (1994) and Ghahramani et al. (2011) found that soil splashed varied very much as a function of the land use, with the highest splash erosion rates occurring over bare soil, and amounts depending on crop type and cover percentage. Agricultural soils are especially prone to splash, since they remain bare during several months every year. Moghadam et al. (2015) found that land use and soil management practices significantly influenced splash erosion rates on farming lands in Iran. Although the total amount of sediment mobilized by interrill processes (rain splash and rain wash) is small compared to rill and tillage erosion, they affect all arable soil surfaces resulting in a significant mobilization of sediment right at the soilatmosphere interface, and thus may have a relevant role in the global carbon cycle (Kuhn et al. 2009).

SOC is mobilized in association with soil particles by rain splash and rain wash (Gregorich et al., 1998). Therefore splash may play a relevant role in the dynamics of SOC, especially under bare conditions such as those of agricultural soils during part of the year. However, there is very little information 
concerning the magnitudes of SOC mobilized by splash from different soil types and conditions. It is known that splash does not have the same effect on all soil particles, and for example differences in the magnitude of splash exist as a function of the size, density and aggregation of the soil particles. In particular, splash tends to be stronger in lighter particles, such as those with a high SOC content. For example, SOC enrichment ratios between 1 and 2.5 times have been recorded in splashed material with respect to the original material at the soil surface (Mermut et al., 1997; Martínez-Mena et al., 2002; Jin et al., 2008; Kuhn, 2007). Small, poorly decomposed plant fragments have an important role on this enrichment of SOC in splashed material, since these light and poorly decomposed vegetal particles are more easily transported than heavier, mineral, particles (Ghadiri and Rose, 1991). The fate of SOC-rich particles splashed from the soil surface is especially important. They may be removed from the site as suspended sediment if trapped by runoff wash on rills and gullies, or else they may accumulate in depositional crusts where SOC is largely unconnected from the soil structure and is exposed to the atmosphere (Le Bissonnais et al., 2005, Kuhn et al., 2009). Either way, it reduces the input of SOC into the soil and has potential for affecting the carbon exchange balance the soils and the atmoshpere. Therefore, a characterization of SOC in the soil particles detached by splash is highly needed.

We undertook an experimental study in order to determine the amount of SOC and enrichment ratios in splashed soil on three soil types, under natural rainfall. To date most studies that examined the contents of SOC on splashed soil particles were carried out in the laboratory or in the field 
under simulated rainfall (Polyakov and Lal, 2004a; Jin et al., 2008). Very few studies were done under natural rainfall, but they did not looked specifically at splash (Martínez-Mena et al., 2008). Our study focused on splash erosion by collecting in splash cups the amount of splash generated after each rainfall event. Precipitation and raindrop characteristics were monitored by means of an optical disdrometer.

The objectives of our study were determining:

1. The differences in SOC concentration and in total SOC mobilized by splash between soil types and size fractions.

2. The differences in SOC concentration between splashed particles and the original soil surface (SOC enrichment) between soil types and size fractions.

3. The effect of rainfall properties (mainly rainfall erosivity) on SOC concentration and total SOC mobilized by splash.

\section{Materials and methods}

\subsection{Experimental site}

The experiment was located in the Aula Dei Experimental Station (414' $30^{\circ}$ N, 0 48'39" O, 230 m. a.s.l), and the monitoring period was between March 2010 and October 2011, spanning a period of 20 months (Figure 1).

Three soils characteristic of the semi-arid central Ebro River depression agricultural and natural lands where considered: a Cambisol, a Gypsisol and a Solonchak (FAO and ISRIC, 1988). These soils are subject to accelerated erosion because they are either occupied by agricultural lands that remain bare during several months every year (Machín and Navas, 1998) or else they 


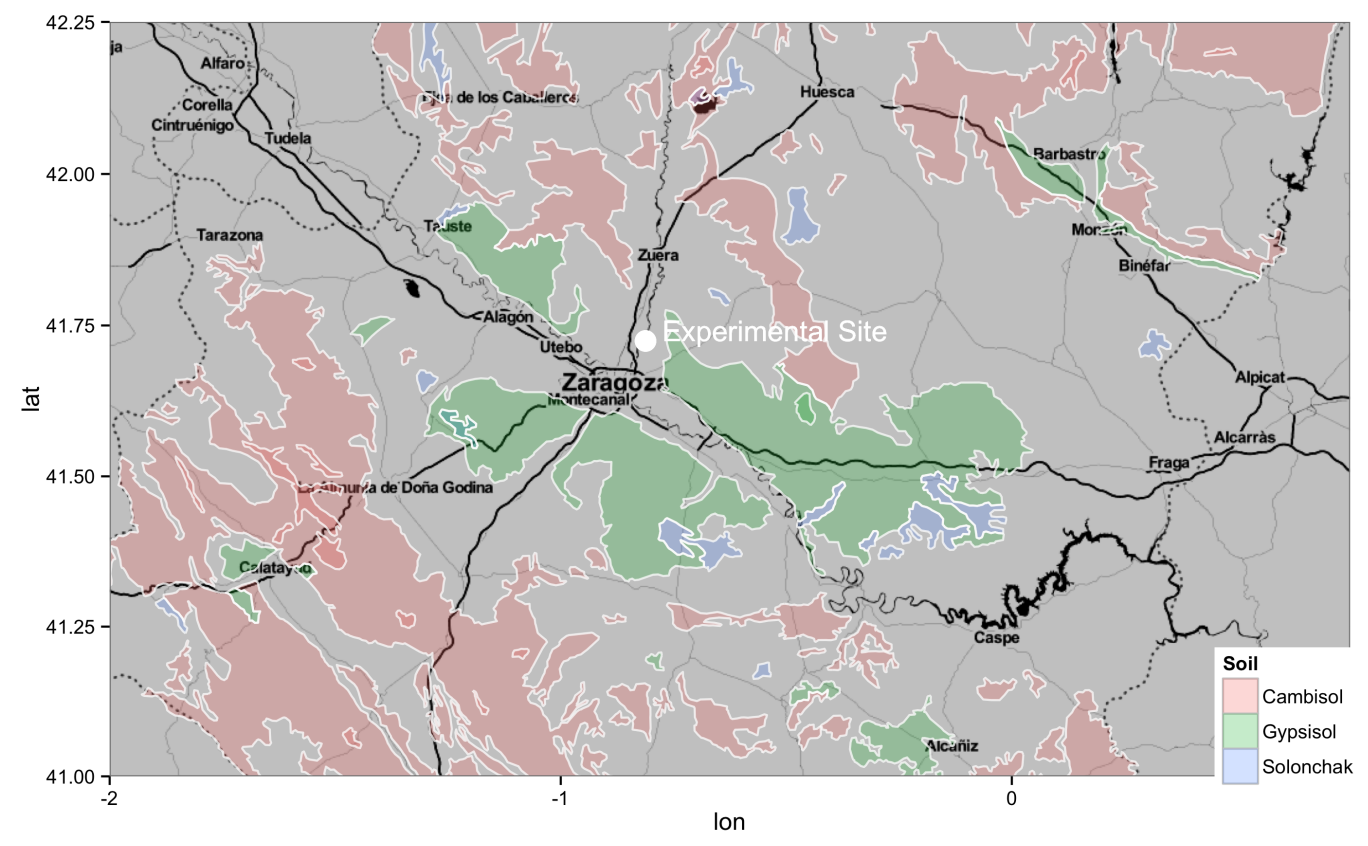

Figure 1: Location of the experimental site and spatial distribution of the three studied soils within the central Ebro Valley. 
Table 1: Soil properties of the three soil types, based on one sample from the upper 20 $\mathrm{cm}$.

\begin{tabular}{|c|c|c|c|c|}
\hline Parameter & Unit & Cambisol & Gypsisol & Solonchak \\
\hline Bulk density & $\mathrm{g} \mathrm{cm}^{-3}$ & 1.31 & 1.18 & 1.31 \\
\hline Porosity & $\%$ & 47.88 & 41.26 & 47.94 \\
\hline \multicolumn{5}{|l|}{ Granulometry: } \\
\hline coarse sand (250 to $2000 \mu \mathrm{m})$ & $\%$ & 2.4 & 7.2 & 3.2 \\
\hline medium sand (100 to $250 \mu \mathrm{m})$ & $\%$ & 13.0 & 16.6 & 13.0 \\
\hline fine sand (50 to $100 \mu \mathrm{m})$ & $\%$ & 11.1 & 9.9 & 12.4 \\
\hline silt $(2$ to $50 \mu \mathrm{m})$ & $\%$ & 59.2 & 55.2 & 55.4 \\
\hline $\operatorname{clay}(<2 \mu \mathrm{m})$ & $\%$ & 14.3 & 11.1 & 16.0 \\
\hline Texture & - & Silt & Sandy loam & Clay loam \\
\hline $\mathrm{pH}$ & - & 8.63 & 8.35 & 8.13 \\
\hline $\mathrm{EC} 1 / 5$ & $\mathrm{dS} \mathrm{m} \mathrm{m}^{-1}$ & 0.37 & 2.4 & 2.33 \\
\hline $\mathrm{EC}(\mathrm{es})$ & - & & 3.84 & 5.92 \\
\hline $\mathrm{CIC}$ & meq $\mathrm{L}^{-1}$ & 149.4 & 119.88 & 155.99 \\
\hline $\mathrm{C}$ & $\%$ & 1.02 & 0.49 & 1.03 \\
\hline $\mathrm{OM}$ & $\%$ & 1.73 & 0.84 & 1.78 \\
\hline $\mathrm{N}$ & $\%$ & 0.11 & 0.07 & 0.06 \\
\hline $\mathrm{C} / \mathrm{N}$ & - & 9.19 & 7.54 & 17.76 \\
\hline $\mathrm{CO}_{3}$ & $\%$ & 35.41 & 15.72 & 35.7 \\
\hline $\mathrm{CaSO}_{4} \cdot 2 \mathrm{H}_{2} \mathrm{O}$ & $\%$ & 2.5 & 61.79 & 3.81 \\
\hline
\end{tabular}

sustain low-coverage plant communities due to their restrictive conditions for vegetation and to the semi-arid climatic conditions prevailing in the region (Guerrero-Campo et al., 1999; Pueyo and Alados, 2007). Soil from the upper $40 \mathrm{~cm}$ was collected from nearby cropping fields and placed in plots of $14 \mathrm{~m} \times 1 \mathrm{~m} \times 0.8 \mathrm{~m}$ in the experimental site. After 20 years, the conditions of these experimental soils are very close to those found in the field, in terms of bulk density and other fundamental properties (Table 1). Details about how these properties were determined are given in the Appendix.

Cambisols are developed over glacis and terraces from fluvial deposits 
CAMBISOL
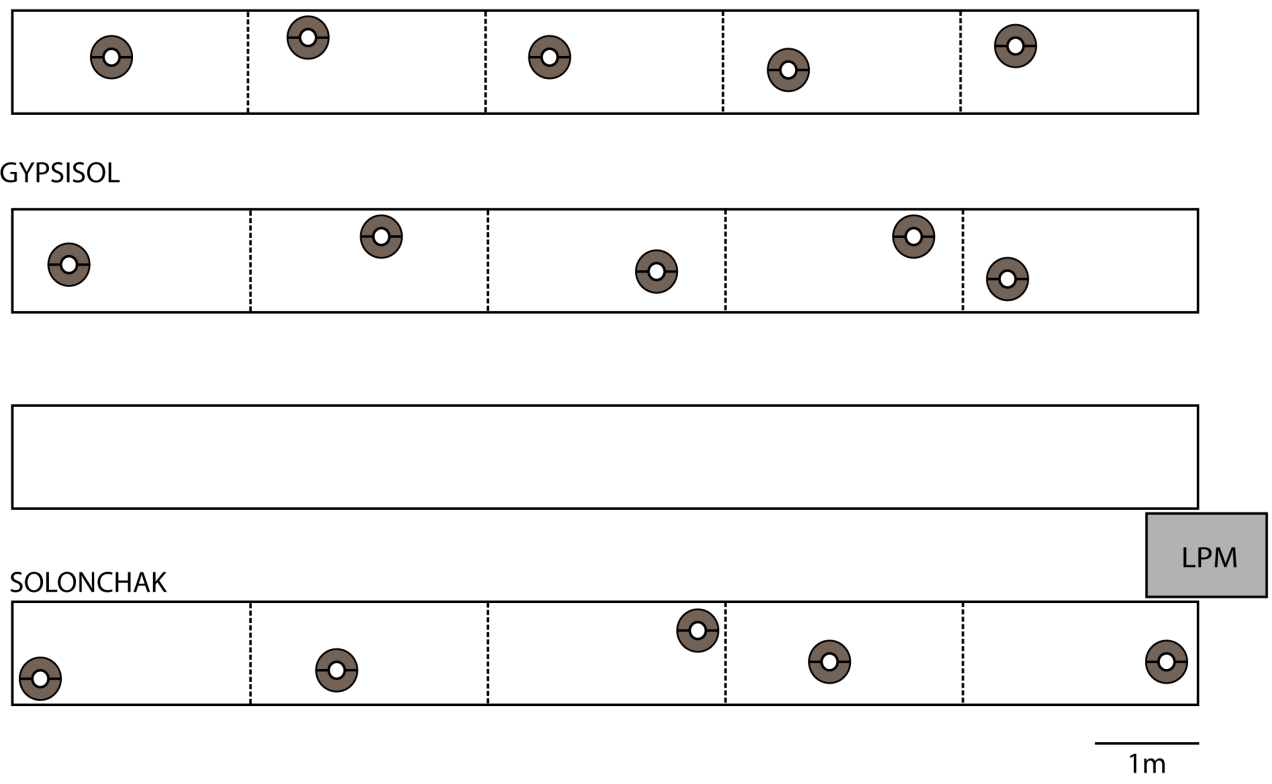

Figure 2: Experimental setup: layout of the three soil strips, the laser precipitation monitor (LPM), and sampling scheme with five splash cups per soil strip deployed in a semi-random pattern.

and marls. Its texture is silty with $25 \%$ pebbles, alkaline $\mathrm{pH}$ and low salinity. They show good drainage, low organic matter content and low gypsum content. Gypsisols are located in colluvial-alluvial valley areas developed over deposits from nearby gypsiferous hills. They have a sandy-loam texture, alkaline $\mathrm{pH}$ and higher salinity than Cambisols. They have a low organic matter and carbonate content and high gypsum content. Solonchaks are found in depressions or level areas. Their texture is clay-loam, and they have poor drainage.

\subsection{Measurement of splash erosion}

The experimental setup is shown in Figure 2.

The three soils were arranged side to side in three plots of $14 \mathrm{~m} \times 1 \mathrm{~m}$ 
at the experimental station, so they were subject to the same precipitation events with equal characteristics of rainfall intensity, duration and kinetic energy. The plots were completely level to avoid slope gradient effects, and the soils were kept bare by mechanical removing of any new seedlings. Apart from that, the soils were kept undisturbed and as close to their natural condition as possible. Although this setup may not be representative of the natural conditions under which these soils appear (with different slope gradients, vegetation cover and soil treatments), it eliminates several factors of variability and eases comparison between the three soils.

Splash erosion was monitored using Morgan-type splash cups (Morgan, 1981). This device consists in a closed circular plate with a smaller circular hole inside that is placed in direct contact with the soil. The inner circle has a sampling area of $0.0085 \mathrm{~m}^{2}$. Soil particles detached by raindrop impacting the bare soil in the inner circle need to jump over a rim of $2.5 \mathrm{~cm}$, and then they are trapped within the outer circle inside the splash cup. The outer rim of the cups is $25 \mathrm{~cm}$ high to avoid contamination of splashed material from outside. To avoid sediment loss by overflowing during very intense storms, some drainage is allowed through small holes at the edges of the cups. A porous membrane was used to let the water slowly drain from the cups while preventing the sediment from escaping.

Five clean splash cups were deployed in each of the three plots and collected after each rainfall event. If sediment was present in the cups it was collected and the cups were deployed in the field again. In order to maintain randomness and to avoid sediment exhaustion effects, the cups were placed each time at a different location within the plots. 
The splash samples were air-dried, weighted and sieved in fractions of silt and clay $(<50 \mu \mathrm{m})$ and fine sand $(50$ to $500 \mu \mathrm{m})$ to account for the SOC associated to the mineral part of these fractions. SOC was analyzed by the dry combustion method using a LECO RC-612 multiphase carbon analyzer designed to differentiate forms of carbon by oxidation temperature (Nelson and Sommers, 1996). A sub-sample of the $<2 \mathrm{~mm}$ fraction is inserted into a quartz tube, heated to $550{ }^{\circ} \mathrm{C}$ and the $\mathrm{SOC}$ is oxidized to $\mathrm{CO} 2$, which is selectively detected by an infrared (IR) gas analyzer. The concentration of SOC was obtained by this procedure (termed $S O C_{c}$, expressed in \%), from which the total SOC mobilized $\left(S O C_{w}\right.$, expressed in mg) were calculated. Due to the minimum amount of soil needed for $\mathrm{C}$ analysis it was not possible to determine the SOC content for splash samples smaller than $0.15 \mathrm{~g}$, so the number of samples for which there were SOC determinations was lower than the total number of splash samples.

The SOC of the soil surface prior to splash was determined using the same procedure for each soil type and grain size fraction (silt-clay and fine sand) at the beginning of the experiment from five samples from the upper $1 \mathrm{~cm}$. These were labelled as 'Control' and kept for comparison with the splash events, which were labelled as 'Splash'.

\subsection{Measurement of rainfall properties}

The characteristics of precipitation events were monitored using a Thies present weather sensor: the Laser Precipitation Monitor, LPM. The LPM is an optical spectro pluviometer (Donnadieu et al., 1969), measuring the diameter and fall velocity of raindrops higher than $0.16 \mathrm{~mm}$ in diameter. These are inferred from the duration and amplitude of obscurations in the 
path of an infrared laser beam between a light emitting diode and a receiver, over a sampling area $A$ of $0.005,14 \mathrm{~m}^{2}$. The LPM records, at pre-defined time intervals, the count of drops binned into 22 diameter and 20 velocity classes, and computes a number of integrated variables including the total precipitation amount $P(\mathrm{~mm})$ and the precipitation intensity $I\left(\mathrm{~mm} \mathrm{~h}^{-1}\right)$. Increased use of optical disdrometers in recent years is enlarging our knowledge of rainfall microphysics, enabling accurate rainfall energy estimation (Angulo-Martínez and Barros, 2015). Here we computed the unit kinetic energy $E\left(\mathrm{~J} \mathrm{~m}^{-2} \mathrm{~mm}^{-1}\right)$ as the sum of the energy $e_{i, j}(\mathrm{~J})$ of each individual drop pertaining to diameter class $i$ and velocity class $j$ :

$$
\begin{aligned}
E & =\frac{\sum_{i} \sum_{j} e_{i, j}}{P A} \\
e_{i, j} & =\frac{1}{2} m_{i} v_{j}^{2} \\
= & \frac{1}{12} 10^{-3} \pi \rho v_{j}^{2} D_{i}^{3}
\end{aligned}
$$

where $m_{i}$ is the mean mass of the drop diameter class $i(\mathrm{~g})$ and $v_{j}$ is the mean velocity of the velocity class $j\left(\mathrm{~ms}^{-1}\right)$. The mean mass was computed by assuming a spherical drop shape, where $\rho$ is the density of water $\left(1 \mathrm{~g} \mathrm{~cm}^{-3}\right)$ and $D_{i}$ is the mean diameter of class $i(\mathrm{~mm})$.

The variables $P, I$ and $E$ were recorded continuously with a time resolution of one minute. The continuous record was then divided into precipitation events. We considered the beginning of every event since the moment when splash cups were placed at the experimental site, and the end of it once splash sediment was found in the cups and they were removed from the field. 
For each event we computed the following properties: i) rainfall duration $D$ (min); ii) precipitation amount $P$; iii) maximum precipitation intensity in 30 minutes during the event $I_{30}\left(\mathrm{~mm} \mathrm{~h}^{-1}\right)$; and iv) unit energy, $E$. The event's rainfall erosivity $E I_{30}\left(\mathrm{MJ} \mathrm{mm} \mathrm{ha}^{-1} \mathrm{~h}-1\right)$ (Renard et al., 1997) was also computed, as follows:

$$
E I_{30}=\left(\sum_{t=1}^{D} 10^{2} E_{t} v_{t}\right) I_{30}
$$

where $E_{t}$ and $v_{t}$ are integrated over the duration of the event.

\subsection{Dataset}

A total of 45 rainfall events were registered during the experiment period. 16 events out of the 45 generated enough material for SOC analysis (only samples containing at least $0.15 \mathrm{~g}$ of both grain size fractions were analyzed). A total of 32 samples were obtained from 15 events for the Cambisol, 42 samples from 16 events for the Solonchak, and 9 samples from 7 events for the Gypsisol. For each sample the following variables were recorded as categorical variables or factors: i) event number; ii) soil type; iii) grain size fraction. The following variables were recorded as continuous (numerical) variables: i) splash (g); ii) EI30 (MJ mm ha ${ }^{-1} \mathrm{~h}-1$ ); iii) $S O C_{c}(\%)$; and iv) $S O C_{w}$ (mg). $S O C_{c}$ and $S O C_{w}$ were determined for each of the two grain size fractions. As an example, the data recorded for one of the events is shown in Table 2. A typical event consisted on a variable number of samples per soil type (here one sample pair for the Cambisol and the Gypsisol, and four pairs for the Solonchack). While the amount of splashed material and SOC varied between samples, the rainfall characteristics only varied between events. 
Table 2: Complete dataset for event $n^{\circ} 13$. In the internal coding of the database, fraction value 1 corresponded to $d<50 \mu \mathrm{m}$ while fraction value 2 corresponded to 50 to $500 \mu \mathrm{m}$.

\begin{tabular}{lrrrrrrrr}
\hline event & soil & fraction & splash & $E$ & $I_{30}$ & $E I_{30}$ & $S O C_{c}$ & $S O C_{w}$ \\
\hline 13 & Cambisol & 1 & 0.22 & 11.70 & 92.90 & 1086.69 & 2.58 & 5.68 \\
13 & Cambisol & 2 & 0.93 & 11.70 & 92.90 & 1086.69 & 7.14 & 66.40 \\
13 & Gypsisol & 1 & 0.18 & 11.70 & 92.90 & 1086.69 & 4.48 & 8.07 \\
13 & Gypsisol & 2 & 0.83 & 11.70 & 92.90 & 1086.69 & 13.60 & 112.88 \\
13 & Solonchak & 2 & 0.30 & 11.70 & 92.90 & 1086.69 & 2.47 & 7.41 \\
13 & Solonchak & 2 & 2.77 & 11.70 & 92.90 & 1086.69 & 4.80 & 132.96 \\
13 & Solonchak & 1 & 0.21 & 11.70 & 92.90 & 1086.69 & 2.52 & 5.29 \\
13 & Solonchak & 2 & 0.69 & 11.70 & 92.90 & 1086.69 & 4.39 & 30.29 \\
13 & Solonchak & 1 & 0.23 & 11.70 & 92.90 & 1086.69 & 2.81 & 6.46 \\
13 & Solonchak & 2 & 0.57 & 11.70 & 92.90 & 1086.69 & 6.42 & 36.59 \\
13 & Solonchak & 1 & 0.16 & 11.70 & 92.90 & 1086.69 & 2.38 & 3.81 \\
13 & Solonchak & 2 & 1.14 & 11.70 & 92.90 & 1086.69 & 3.20 & 36.48 \\
\hline
\end{tabular}




\subsection{Statistical analysis}

This resulted in a relatively complex general linear model configuration, including two factors (soil type and grain size fraction); several covariates (rainfall erosivity and splash amount); repeated measurements (one for each rainfall event) and between 1 and 5 measurements per event and soil type combination. The different events were included in the model as a random factor, while the variable number of measurements per event were considered as replicates.

Alternative model configurations of $S O C_{c}$ and $S O C_{w}$ (dependent variables) against an increasing number of factors, covariates and their interactions were tested by means of Bayes factors (BFs) (Jeffreys, 1961; Kass and Raftery, 1995). BFs constitute a hypothesis testing method often used for the comparison of multiple models. They present a number of advantages over (more common) frequentist methods for model selection, since they i) avoid model selection bias; ii) allow for non-nested models to be compared; iii) are not affected by sample size effects; iv) naturally penalize against model dimensionality and thus reduce model overfitting; and v) evaluate evidence in favor of the null hypothesis (Rouder and Morey, 2012). BFs may be defined as follows: given a model selection problem in which we have to choose on the basis of observed data $y$ between two alternative models $\mathcal{M}_{1}$ and $\mathcal{M}_{2}$ (where the hypothesis is usually $\mathcal{M}_{1}>\mathcal{M}_{2}$ ), parameterized by model parameter vectors $\Theta_{1}$ and $\Theta_{2}$, the $\mathrm{BF}$ is given by: 
Table 3: Interpretation of Bayes factors.

\begin{tabular}{cc}
\hline$B F$ & strength of evidence \\
\hline$[-\infty, 0.1]$ & strong against \\
$(0.1,1 / 3]$ & substantial against \\
$(1 / 3,1]$ & barely worth mentioning against \\
$(1,3]$ & barely worth mentioning for \\
$(3,10]$ & substantial for \\
$(10,30]$ & strong for \\
$(30,100]$ & very strong for \\
$(100, \infty]$ & decisive for \\
\hline
\end{tabular}

$$
\begin{aligned}
B F & =\frac{p\left(y \mid \mathcal{M}_{1}\right)}{p\left(y \mid \mathcal{M}_{2}\right)} \\
& =\frac{\int p\left(y \mid \Theta_{1}, \mathcal{M}_{1}\right) p\left(\Theta_{1} \mid \mathcal{M}_{1} d \Theta_{1}\right)}{\int p\left(y \mid \Theta_{2}, \mathcal{M}_{2}\right) p\left(\Theta_{2} \mid \mathcal{M}_{2} d \Theta_{2}\right)}
\end{aligned}
$$

where $p\left(y \mid \mathcal{M}_{1}\right)$ is the marginal likelihood of the data in model $\mathcal{M}_{1}$ (i.e., the probability that these data are produced under the constraints of this model). Thus, BFs represent the ratio of the odds of the data's probability under two competing models (Goodman, 2001). An interpretation of BFs in terms of strength of evidence is shown in Table 3 (Jeffreys, 1961). Although other interpretations exist, we shall abide to this classical reference.

BFs are cumbersome to compute, but a number of efficient numerical integrations have been proposed. Monte Carlo Markov Chain (MCMC) strategies such as the Gibbs sampler may be used for approximating the posterior distribution of the model parameters, allowing for very detailed interpreta- 
tion. Here we used the BayesFactor package, as implemented in R (Morey et al., 2011; Rouder and Morey, 2013).

\section{Results}

\subsection{Exploratory analysis}

Considering the amount of splash (Figure 3) a clear difference was apparent between the two size fractions, with higher values corresponding to the larger fraction. On the other hand there was no clear evidence of differences between the three soil types, irrespective of the grain size fraction. The figure also shows the splash samples for which SOC was measured. It was not possible to analyze SOC for all the splash samples, since in a number of cases at least one of the two fractions did not contain enough material for the analysis. This resulted in an imbalanced sample, with a smaller number of cases for the Gypsisol $(\mathrm{N}=18)$ as compared to the Solonchak $(\mathrm{N}=84)$ and the Cambisol ( $\mathrm{N}=64)$. In general, the samples for which SOC could be analyzed were taken from the higher part of the range of splash amount, for each soil type. Also, the samples from the Gypsisol tended to correspond to larger splash amounts than those from the two other soils.

Differences in SOC concentration $\left(S O C_{c}\right)$ were apparent between soils, between size fractions, and also between control and splash samples (Figure 4). In the control samples the Gypsisol tended to have lower SOC concentration, especially in the smallest fraction, while the Cambisol tended to have the largest values of SOC concentration. This trend was inverted in the splash samples, which showed a tendency to a higher SOC concentration in the Gypsisol and lower in the Cambisol. When comparing the splash samples 


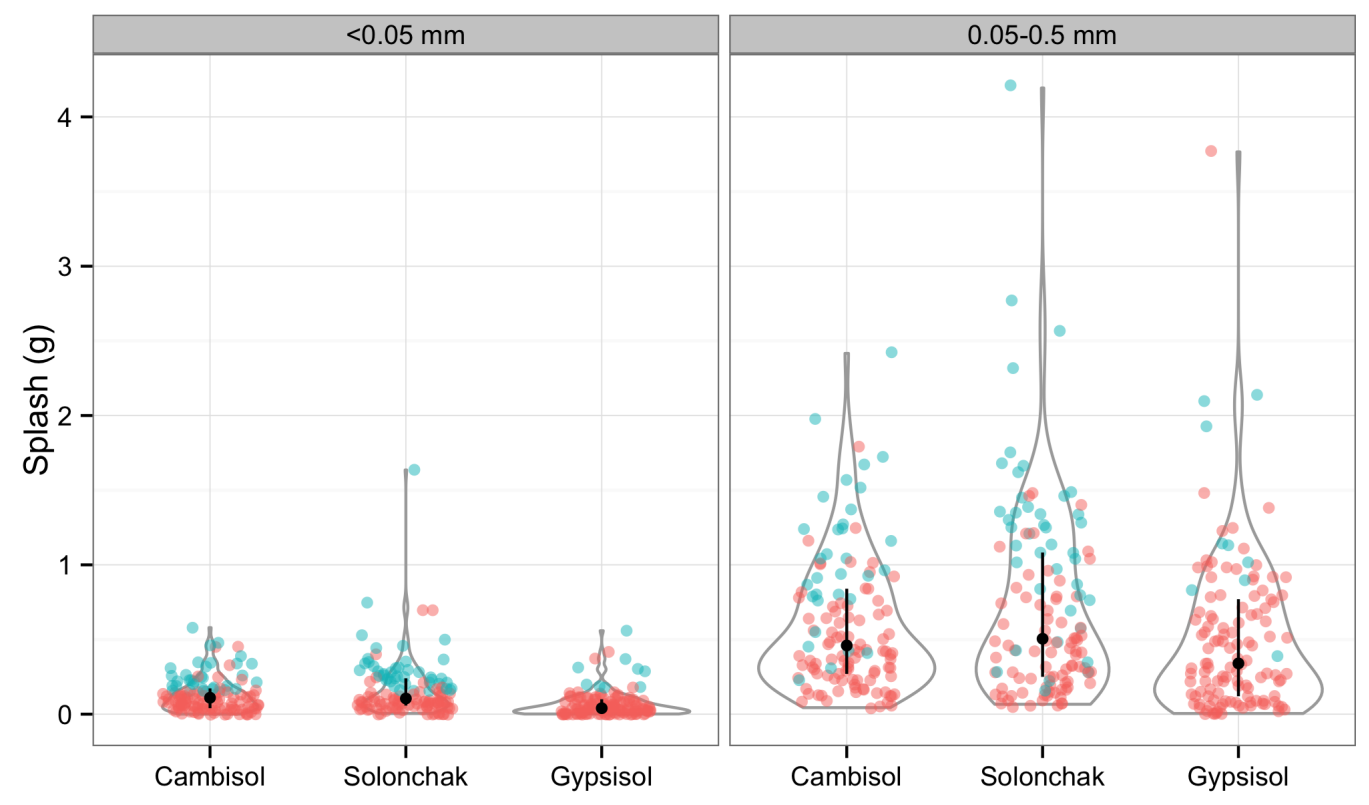

Figure 3: Violin plot: distribution of splash amount stratified per soil type and grain size fraction: individual observations (jittered dots), median (black dot), inter-quantile range (black line), and density (grey line). Splash samples for which the SOC concentration was analyzed are shown in blue color.

with the control samples an enrichment in SOC concentration was apparent in the three soil types. This enrichment was strongest in the Gypsisol and lowest in the Cambisol, for which it was not clear that an enrichment exists at all.

The total SOC mobilized by splash results from the combination of the two previous variables, i.e. splash amount and SOC concentration (Figure 5). The highest SOC values corresponded to the coarser (50 to $500 \mu \mathrm{m}$ ) fraction, as expected from the combined result of a higher splash amount and higher SOC concentration. Also, differences were evident between soil types, with higher SOC amounts mobilized in the Gypsisol and lowest in the Cambisol. 


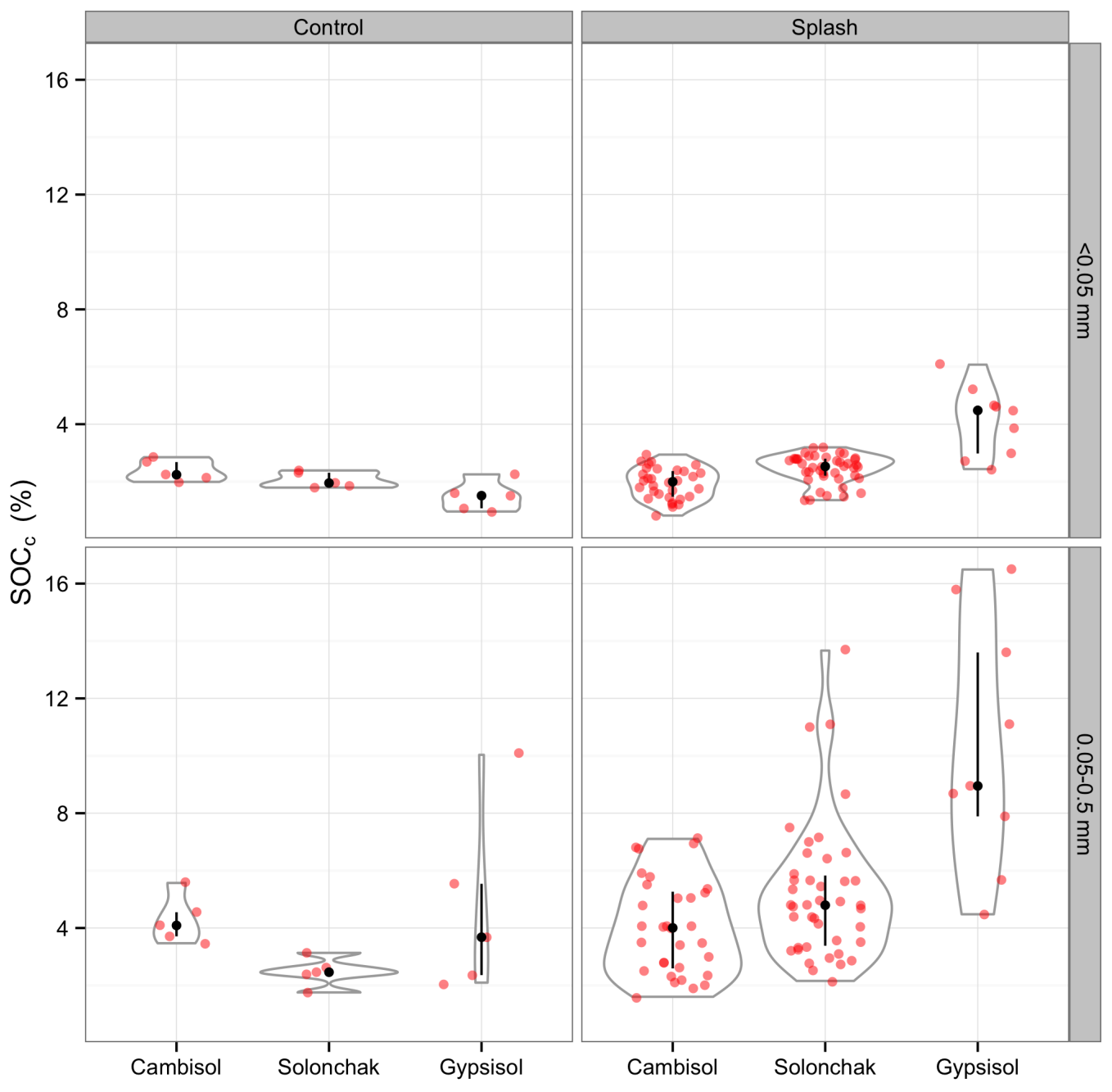

Figure 4: Distribution of SOC concentration $\left(S O C_{c}\right)$ in control and splash samples, stratified per soil type and grain size fraction: individual observations (jittered red dots), median (black dot), inter-quantile range (black line), and density (grey line). 

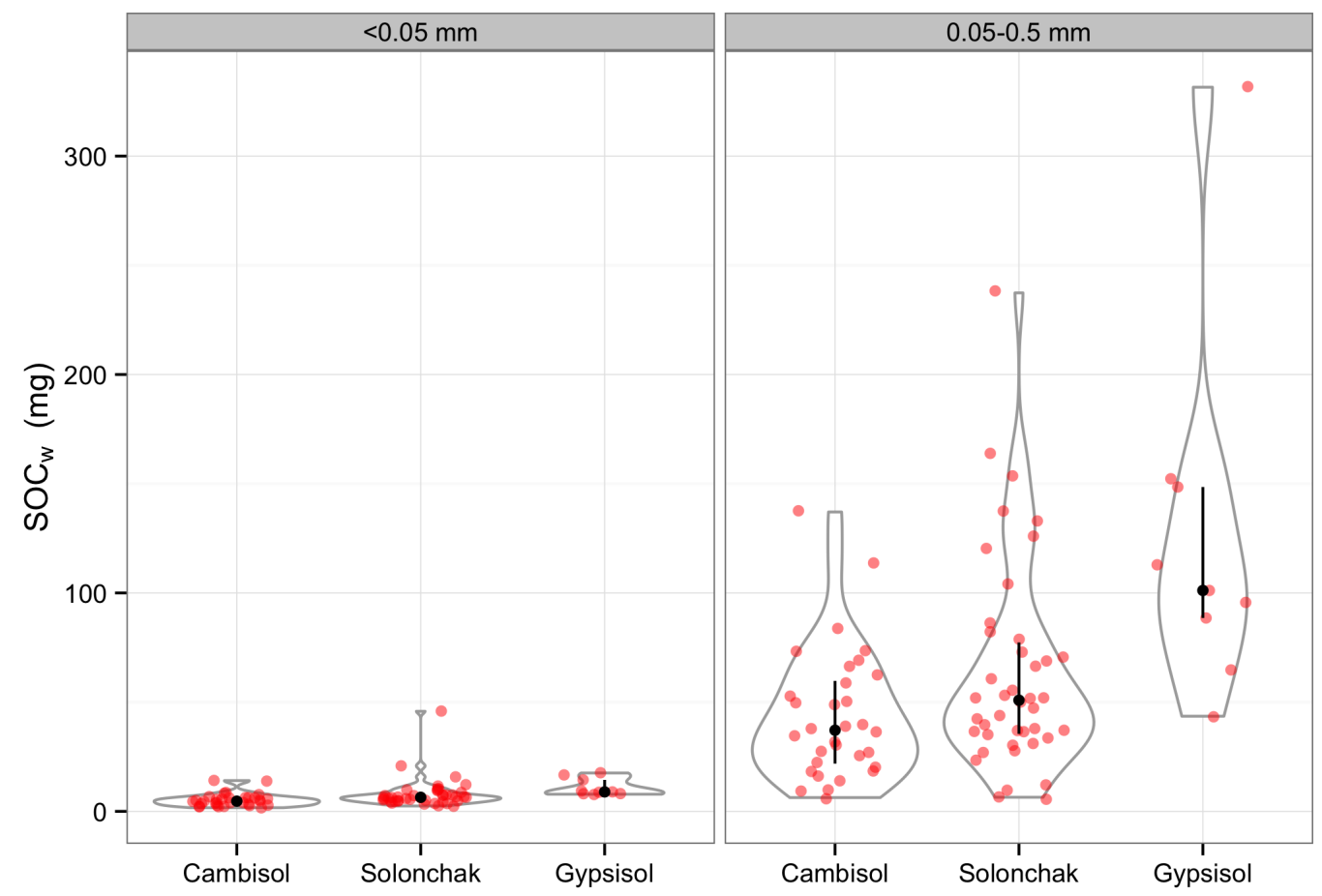

Figure 5: Distribution of total SOC $\left(S O C_{w}\right)$ mobilized by splash, stratified per soil type and grain size fraction: individual observations (jittered dots), median (black dot) and interquantile range (black line), and density (grey line). 


\subsection{SOC concentration}

\subsubsection{Effect of grain size fraction and soil type on SOC concentration}

We started testing only the effect of the two experimental factors, i.e. the grain size fraction and the soil type, on the SOC concentration of the splashed material. The experimental data determined a decisive preference $\left(B F=3.2 \times 10^{24}\right)$ for the most complex model including the effect of grain size fraction, soil type and their interaction over the null model assuming no effects at all. There was also a very strong preference $(B F=64.0)$ of this complete model over the model with the fraction and soil type, but no interaction between them. A pairwise comparison between all possible model configurations is given in Table B.6.

The above models included the event number as a random effect, configuring a model with repeated measurements. A comparison between the optimum model with and without this random effect resulted in a decisive $\left(B F=5.7 \times 10^{3}\right)$ evidence supporting the existence of a random effect, indicating that there were important differences between rainfall events. These differences could possibly be related to differences in the rainfall characteristics or in the amount of splash generated at each event, so the effect of this covariates was tested next.

\subsubsection{Effect of rainfall erosivity and splash on SOC concentration}

Differences between rainfall events might be due to nuisance effects (i.e. a random effect, as we modeled it so far), or they might arise from differences in the rainfall characteristics between events. So next we tested the effect of rainfall erosivity $\left(E I_{30}\right)$ and of the splash amount on SOC concentration by adding these two covariates to the best model so far (Table B.7). 
The experimental data provided no conclusive support in favor or against the models including the effect of splash $(B F=0.52)$, rainfall erosivity $(B F=1.10)$ or both variables $(B F=0.79)$. The model with the two variables and their interaction was rejected $(B F=5.67)$. In conclusion, no evidences were found for an effect of the amount of splash or the rainfall erosivity in the SOC concentration of splashed samples.

\subsubsection{Differences in SOC concentration between splashed and original ma-} terial

A relevant question is whether SOC concentration was different in the splashed material when compared to the original soil surface. In order to test this we compared the best model so far with a more complete model including the control samples and the interaction between these and the soil type. The data provided decisive evidence $\left(\mathrm{BF}=7.7 \times 10^{3}\right)$ favouring the existence of differences in SOC concentration between the original soil particles (control) and the splashed particles, but only if the interaction with the soil type was also considered. That is, there are differences in SOC concentration between the soil and splashed particles, and these differences vary between soil types.

\subsubsection{Model parameters}

The model parameters can be estimated by sampling the posterior distribution of the optimum model obtained so far, that is $\mathcal{M}_{10}$ (Table 4). For each model parameter its mean value, standard deviation and limits of the $95 \%$ confidence interval are shown. The sign of the mean parameter indicates the sign of the effect of each covariate in SOC concentration. The confidence interval of the model parameters can be used for checking the significance 
of each covariate. If the interval does not contain the null value (0) within its boundaries, there is a strong evidence that a particular covariate has an effect on the dependent variable.

The global mean SOC concentration was 4.06\%. The Gypsisol had on average $1.36 \%$ more $S O C_{c}$, while the Cambisol and the Solonchak had lower than average $S O C_{c}$ (by -0.54 and $-0.83 \%$, respectively). The coarser grain size fraction (50 to $500 \mu \mathrm{m}$, coded as Fraction 2) had $1.57 \%$ higher $S O C_{c}$, while the finer fraction $(<50 \mu \mathrm{m}$, coded as Fraction 1) resulted in a lower $S O C_{c}$ by the same amount. This difference between grain size fractions was accentuated in the case of the Gypsisol $( \pm 0.81 \%)$, while it was reduced in the case of the other two soils (by $\pm 0.89 \%$ for the Cambisol and $\pm 0.25 \%$ for the Solonchak).

The splash samples had on average $0.49 \%$ higher $S O C_{c}$ than the global mean, while the control samples had lower $S O C_{c}$ by the same amount. SOC enrichment ratios can be computed from the model parameters for the three soil types. The enrichment ratio is 2.33 for the Gypsisol (i.e., splash samples have on average more than twice $S O C_{c}$ than the original material from the soil surface). For the Cambisol and the Solonchak this value decreases to 1.26 and 1.16, respectively.

Differences between events (random effect, not shown) ranged between $+2.04 \%$ for event number 33 or $+1.23 \%$ for event number 2 (the second in magnitude), and $-1.08 \%$ for event 45 . The error variance $\left(\sigma^{2}\right)$ was 2.47 .

\subsection{Total soil organic carbon}

As interesting as analyzing the concentration SOC in the splashed samples is the the total amount of $\operatorname{SOC}\left(S O C_{w}\right)$ mobilized by splash in each 
Table 4: Model parameters for the fixed effects part of $\mathcal{M}_{12}: S O C c$ as a function of size fraction, soil type, control vs. splash, and the interaction between soil and fraction and between fraction and control vs. splash.

\begin{tabular}{lccc}
\hline & Mean & St. Dev. & $95 \%$ Conf. Int. \\
\hline$\mu$ (grand mean) & 4.06 & 0.53 & $(2.96,5.06)$ \\
Fraction1 $(<0.05 m m)$ & -1.35 & 0.16 & $(-1.66,-1.03)$ \\
Fraction2 $(0.05-0.5 m m)$ & 1.35 & 0.16 & $(1.03,1.66)$ \\
Cambisol & -0.54 & 0.22 & $(-0.97,-0.12)$ \\
Solonchak & -0.83 & 0.22 & $(-1.26,-0.4)$ \\
Gypsisol & 1.37 & 0.25 & $(0.88,1.85)$ \\
Control & -0.49 & 0.5 & $(-1.56,0.4)$ \\
Splash & 0.49 & 0.5 & $(-0.4,1.56)$ \\
Cambisol.Fraction1 & 0.56 & 0.17 & $(0.24,0.89)$ \\
Cambisol.Fraction2 & -0.56 & 0.17 & $(-0.89,-0.24)$ \\
Solonchak.Fraction1 & 0.37 & 0.16 & $(0.06,0.68)$ \\
Solonchak.Fraction2 & -0.37 & 0.16 & $(-0.68,-0.06)$ \\
Gypsisol.Fraction1 & -0.93 & 0.22 & $(-1.37,-0.49)$ \\
Gypsisol.Fraction2 & 0.93 & 0.22 & $(0.49,1.37)$ \\
Cambisol.Control & 0.89 & 0.22 & $(0.46,1.33)$ \\
Cambisol.Splash & -0.89 & 0.22 & $(-1.33,-0.46)$ \\
Solonchak.Control & 0.25 & 0.22 & $(-0.17,0.68)$ \\
Solonchak.Splash & -0.25 & 0.22 & $(-0.68,0.17)$ \\
Gypsisol.Control & -1.14 & 0.25 & $(-1.63,-0.64)$ \\
Gypsisol.Splash & 1.14 & 0.25 & $(0.64,1.63)$ \\
Fraction1.Control & 0.38 & 0.15 & $(0.08,0.69)$ \\
Fraction1.Splash & -0.38 & 0.15 & $(-0.69,-0.08)$ \\
Fraction2.Control & -0.38 & 0.15 & $(-0.69,-0.08)$ \\
Fraction2.Splash & 0.38 & 0.15 & $(0.08,0.69)$ \\
\hline
\end{tabular}


event. The total SOC, as it was mentioned above, is a function of the SOC concentration and the splash amount.

The best model for $S O C_{w}$ included the soil type, size fraction, splash amount and the interaction between splash and fraction, that is model $\mathcal{M}_{11}$ (Table B.9). Other variables such as the rainfall erosivity (EI30), or interactions, did not yield better models so these models were rejected.

The model parameters show the importance of the splash amount in determining the total mass of SOC mobilized, with a coefficient of almost $13 \mathrm{mg}$ of SOC mobilized for each gram of splashed material (Table 5). A large difference exists also between size fractions, amounting to $\pm 32 \mathrm{mg}$. A smaller but also significant difference exists between soil types, with the Gypsisol yielding significantly higher amount of splashed SOC $(13.8 \mathrm{mg})$. The difference between size fractions are higher in the Gypsisol than in the other two soil types $\pm 12.60 \mathrm{mg}$, while it is smaller for the Cambisol and the Solochak ( $\pm 7.80 \mathrm{mg}$ and $\pm 4.81 \mathrm{mg}$, respectively). Similarly, the coefficient of splash is higher in the coarser fraction than in the finer one $( \pm 10.38)$, that is there is a stronger control of the magnitude of the event in the coarse fraction.

\section{Discussion}

We found higher SOC concentrations in the coarse fraction (50 to $500 \mu \mathrm{m}$ ) for the three soils, and in the Gypsisol with respect to the other two soils. This difference between grain size fractions was also stronger in the Gypsisol. Of the three soils, the Gypsisol has the coarsest texture (sandy loam) and the lowest SOC concentration. It is also characterized by a highly mono-mineral composition with a low content of clay minerals that hinders particle aggre- 
Table 5: Model parameters for the fixed effects part of $\mathcal{M}_{23}$ : SOCw as a function of splash amount, soil type, size fraction, and the interactions between soil and fraction and splash and fraction.

\begin{tabular}{lccc}
\hline & Mean & St. Dev. & $95 \%$ Conf. Int. \\
\hline$\mu$ (grand mean) & 40.47 & 4.53 & $(31.48,49.45)$ \\
splash & 12.89 & 1.69 & $(9.56,16.17)$ \\
Fraction1 $(<0.05 m m)$ & -31.65 & 2.55 & $(-36.64,-26.62)$ \\
Fraction2 $(0.05-0.5 m m)$ & 31.65 & 2.55 & $(26.62,36.64)$ \\
Cambisol & -8.39 & 3.38 & $(-15.17,-1.93)$ \\
Solonchak & -5.44 & 3.04 & $(-11.42,0.41)$ \\
Gypsisol & 13.83 & 4.99 & $(4.39,23.77)$ \\
splash.Fraction1 & -10.36 & 1.27 & $(-12.85,-7.86)$ \\
splash.Fraction2 & 10.36 & 1.27 & $(7.86,12.85)$ \\
Cambisol.Fraction1 & 7.88 & 3.12 & $(1.9,14.07)$ \\
Cambisol.Fraction2 & -7.88 & 3.12 & $(-14.07,-1.9)$ \\
Solonchak.Fraction1 & 4.81 & 2.86 & $(-0.71,10.47)$ \\
Solonchak.Fraction2 & -4.81 & 2.86 & $(-10.47,0.71)$ \\
Gypsisol.Fraction1 & -12.69 & 4.61 & $(-21.82,-3.94)$ \\
Gypsisol.Fraction2 & 12.69 & 4.61 & $(3.94,21.82)$ \\
\hline
\end{tabular}


gation since it restricts the organic matter to be fixed on the frayed edge sites of the clays. This in turn leaves fresh organic particles loose and easily mobilized by splash, so splash further enhances the inherent difficulties for forming soil aggregates characteristic of the Gypsisol, and hinders the incorporation of SOC into the more stable carbon pools. Rainfall simulation studies focusing on three different gypseous soils of the same area found higher suspended and dissolved sediment production from the soil with the highest SOC content, supporting that on this soils the presence of organic matter is not necessarily related to higher particle aggregation and soil protection (Navas, 1990, 1993). This result also coincides with the experimental findings of Kuhn (2007), who found that erodibility of SOC by interrill erosion processes (including rain splash and rain wash) was inversely related to the SOC concentration of the parent soil.

We found higher SOC concentrations on the splashed material with respect to the parent material, for both size fractions and all soils. However, large differences existed between soils, as shown by SOC enrichment ratios (the ratio between the SOC concentrations of the splashed and parent material). These ranged between 1.16 and 1.26 for the Cambisol and the Solonchak, implying a relatively low enrichment, and 2.33 for the Gypsisol. Previous studies that measured SOC enrichment in runoff wash sediment reported ratios between 1 and 2.5, with typical values in the range of $1-1.5$ (Jin et al., 2008; Martínez-Mena et al., 2012, Polyakov and Lal, 2004b). Our experimental data, coming from rainfall splash alone, are comparable in magnitude to these values, suggesting that splash is the main contributor to SOC enrichment in interrill erosion. 
nost studies reported higher enrichment ratios in the fine fractions (Palis et al., 1997; Polyakov and Lal, 2004a; Martínez-Mena et al., 2012). MartínezMena et al. (2012) indicates that enrichment ratios "tend to be higher for more aggregated soils with high concentrations of clay than less aggregated and coarse-textured soils". In our case, however, the opposite pattern was found, since higher SOC concentrations and enrichment was found on the coarse fraction (50 to $500 \mu \mathrm{m}$ ), especially on the Gypsisol. In soils with low contents of organic matter and clay particles such as the ones in this study, it seems that poor aggregation leads to less enrichment in the fine fraction, while the coarser loose organic particles are more susceptible to be mobilized. Additionally, it could be argued that splash erosion produces a stronger selection of lighter particles than runoff wash.

Several authors mentioned an effect of rainfall properties in SOC enrichment, but discrepancies can be found between studies. While higher SOC enrichment was described under low intensity rainfalls (Jacinthe et al., 2004), other authors recorded higher SOC enrichment under high intensity storms (Strickland et al., 2005, Ramos and Martínez-Casasnovas, 2006). We found that rainfall erosivity did not have an effect on SOC concentration, and no conclusive relationship was found between SOC concentration and the amount of splash, for the three soils and two size fractions considered. That is, SOC concentration tended to remain constant irrespective of the event intensity and of the amount of splash mobilized. Studies based on simulated rainfall described an exhaustion effect, since SOC concentration in runoff sediments decreased with the event duration. In our study the less intense events were sub-represented due to the minimum amount of sample needed 
for the SOC analysis, and this constrained the range of events that were analyzed. It is possible that an effect of the event intensity or the amount of splash would have been found if the less intense events were included in the analysis.

The amount of splash generated was the main variable determining the total amount of SOC mobilized per event, while SOC concentration and SOC enrichment were secondary in comparison. No differences were found between soils in the amount of splash generated. The rainfall properties (intensity and duration, but also the drop size distribution) determine the kinetic energy of rainfall events, and thus control the amount of splash. In a previous study we found that rainfall erosivity, as measured by the $E I_{30}$ index, determined the amount of splash in the same three soils (Angulo-Martínez et al., 2012). Therefore, rainfall erosivity determines the amount of SOC mobilized by splash per event.

\section{Conclusions}

We set up a experimental study for measuring SOC concentration and SOC enrichment due to splash erosion on three soils under natural rainfall conditions. We found that splash acts with preference on loose coarse particles, rich in organic carbon in comparison with the underlying soil material. This explains the enrichment of SOC found in the splashed material with respect to the original soil. Although precipitation characteristics (rainfall erosivity) did not affect SOC concentration, they determined the amount of splash generated and thus it was the main factor determining the net mobilization of SOC by splash erosion. We also found significant differences 
between the three soils analyzed (a Cambisol, a Gypsisol and a Solonchak), with the Gypsisol showing the strongest SOC enrichment in the splashed material and the largest difference between size fractions.

Our results show that rainfall splash has an important role on the fate of SOC on the soils under study, as it is probably the case of other soils. This is especially relevant in the case of the Gypsisol, for which splash may restrict the incorporation of fresh SOC into more stable carbon pools and prevent the formation of soil aggregates, leading to increased erodibility.

\section{Acknowledgements}

This work has been supported by the research projects CGL2011—24185 and CGL2011 - 25486, financed by the Spanish Ministerio de Economía y Competitividad (MINECO) and EU-FEDER. 
Angulo-Martínez, M., Barros, A., 2015. Measurement uncertainty in rainfall kinetic energy and intensity relationships for soil erosion studies: An evaluation using parsivel disdrometers in the southern appalachian mountains. Geomorphology 228, 28-40.

Angulo-Martínez, M., Beguería, S., Navas, A., Machín, J., 2012. Splash erosion under natural rainfall on three soil types in NE Spain. Geomorphology $175-176,38-44$.

Donnadieu, G., Dubosclard, G., Godard, S., 1969. Un pluviomètre photoélectrique pour la determination simultanée des espectres dimensionnel et de vitesse de chute des gouttes de pluie. Journal de Recherches Atmospheriques 4, 37-46.

FAO, ISRIC, 1988. The revised legend of the FAO-UNESCO soil map of the World. Vol. 1988-01 of ISRIC Report. Wageningen, Food and Agriculture Organization of the United Nations (FAO) and ISRIC-World Soil Information.

Ghadiri, H., Rose, C. W., 1991. Sorbed chemical transport in overland flow: I. A nutrient and pesticide enrichment mechanism. Journal of Environmental Quality 20, 628-633.

Ghahramani, A., Ishikawa, Y., Gomi, T., Shiraki, K., Miyata, S., 2011. Effect of ground cover on splash and sheetwash erosion over a steep forested hillslope: A plot-scale study. Catena 85 (1), 34-47.

Goodman, S., 2001. Of p-values and Bayes: a modest proposal). Epidemiology $12,295-297$. 
Gregorich, E., Greer, K., Anderson, D., Liang, B., 1998. Carbon distribution and losses: erosion and deposition effects. Soil and Tillage Research 47 (3), 291-302.

Guerrero-Campo, J., Alberto, F., Hodgson, J., García-Ruiz, J. M., Montserrat-Martí, G., 1999. Plant community patterns in a gypsum area of ne spain. i. interactions with topographic factors and soil erosion. Journal of Arid Environments 41 (4), 401-410.

Hairsine, P., Rose, C., 1991. Rainfall detachment and deposition: sediment transport in the absence of flow-driven processes. Soil Science Society of America Journal 55 (2), 320-324.

Jacinthe, P.-A., Lal, R., Owens, L., Hothem, D., 2004. Transport of labile carbon in runoff as affected by land use and rainfall characteristics. Soil and Tillage Research 77 (2), 111-123.

Jeffreys, H., 1961. Theory of Probability. Oxford University Press).

Jin, K., Cornelis, W., Schiette, W., Lu, J., Buysse, T., Baert, H., Wu, H., Yao, Y., Cai, D., Jin, J., Neve, S., Hartmann, R., Gabriels, D., 2008. Redistribution and loss of soil organic carbon by overland flow under various soil management practices on the Chinese Loess Plateau. Sol and Use Management 24, 181-191.

Kass, R., Raftery, A., 1995. Bayes factors). Journal of the American Statistical Association 90, 773-795.

Kuhn, N. J., 2007. Erodibility of soil and organic matter: independence of 
organic matter resistance to interrill erosion. Earth Surface Processes and Landforms 32 (5), 794-802.

Kuhn, N. J., Hoffmann, T., Schwanghart, W., Dotterweich, M., 2009. Agricultural soil erosion and global carbon cycle: controversy over? Earth Surface Processes and Landforms 34 (7), 1033-1038.

Lal, R., 2005. Soil erosion and carbon dynamics. Soil and Tillage Research 81, 137-142.

Lal, R., Griffin, M., Apt, J., Lave, L., Morgan, M., 2004. Managing soil carbon. Science 304, 393.

Le Bissonnais, Y., Cerdan, O., Lecomte, V., Benkhadra, H., Souchère, V., Martin, P., 2005. Variability of soil surface characteristics influencing runoff and interrill erosion. Catena 62 (2), 111-124.

Li, Y., Zhang, Q, W., Reicosky, D., Bai, L., Lindstrom, M., Li, L., 2006. Using $137 \mathrm{Cs}$ and $210 \mathrm{Pbex}$ for quantifying soil organic carbon redistribution affected by intensive tillage on steep slopes. Soil and Tillage Research 86, $176-184$.

Machín, J., Navas, A., 1998. Spatial analysis of gypsiferous soils in the Zaragoza province (Spain), using GIS as an aid to conservation. Geoderma $87,57-66$.

Martínez-Mena, M., López, J., Almagro, M., Albaladejo, J., Castillo, V., Ortiz, R., Boix-Fayos, C., 2012. Organic carbon enrichment in sediments: effects of rainfall characteristics under different land uses in a Mediterranean area. Catena 94, 36-42. 
Martínez-Mena, M., López, J., Almagro, M., Boix-Fayos, C., Albaladejo, J., 2008. Effect of water erosion and cultivation on the soil carbon stock in a semiarid area of South-East Spain. Soil and Tillage Research 99 (1), $119-129$.

Martínez-Mena, M., Rogel, J. A., Castillo, V., Albaladejo, J., 2002. Organic carbon and nitrogen losses influenced by vegetation removal in a semiarid Mediterranean soil. Biogeochemistry 61 (3), 309-321.

Mati, B., 1994. Splash transport of soil on a slope under various crop covers. Agricultural Water Management 26, 59-66.

Mermut, A., Luk, S., Römkens, M., Poesen, J., 1997. Soil loss by splash and wash during rainfall from two loess soils. Geoderma 75 (3), 203-214.

Meyer, L., Wischmeier, W., 1969. Mathematical simulation of the process of soil erosion by water. Amer Soc Agr Eng Trans Asae.

Moghadam, B. K., Jabarifar, M., Bagheri, M., Shahbazi, E., 2015. Effects of land use change on soil splash erosion in the semi-arid region of iran. Geoderma 241, 210-220.

Morey, R., Rouder, J., Pratte, M., Speckman, P., 2011. Using MCMC chain outputs to efficiently estimate Bayes factors). Journal of Mathematical Psychology 55, 368-378.

Morgan, R., 1981. Field measurement of splash erosion. International Association of Scientific Hydrology Publication 133, 373-82. 
Navas, A., 1990. The effect of simulated runoff on the erosion of gypsiferous soils. Land Degradation \& Development 2 (2), 117-126.

Navas, A., 1993. Soil losses under simulated rainfall in semi-arid shrublands of the Ebro Valley, Spain. Soil use and management 9 (4), 152-157.

Navas, A., Gaspar, L., Quijano, L., López-Vicente, M., Machín, J., 2012. Patterns of soil organic carbon and nitrogen in relation to soil movement under different land uses in mountain fields (South Central Pyrenees). Catena 94, 43-52.

Nelson, D., Sommers, L., 1996. Total carbon, organic carbon, and organic matter. In: Page, A., Miller, R., Keeney, D. (Eds.), Methods of Soil Analysis, Part 2, 2nd Edition. No. 9 in Agronomy Monograph. American Society of Agronomy, Soil Science Society of America, Madison, WI, pp. $961-1010$.

Palis, R., Ghandiri, H., Rose, C., Saffigna, P., 1997. Soil erosion and nutrient loss. III. Changes in the enrichment ratio of total nitrogen and organic carbon under rainfall detachment and entrainment. Australian Journal of Soil Research 35 (4), 891-905.

Polyakov, V., Lal, R., 2004a. Modeling soil organic matter dynamics as affected by soil water erosion. Environment International 30 (4), 547-556.

Polyakov, V., Lal, R., 2004b. Soil erosion and carbon dynamics under simulated rainfall. Soil Science 169 (8), 590-599.

Post, W. M., Kwon, K. C., 2000. Soil carbon sequestration and land-use change: processes and potential. Global Change Biology 6 (3), 317-327. 
Pueyo, Y., Alados, C., 2007. Abiotic factors determining vegetation patterns in a semi-arid Mediterranean landscape: different responses on gypsum and non-gypsum substrates. Journal of Arid Environments 69 (3), 490-505.

Quansah, C., 1981. The effect of soil type, slope, rain intensity and their interactions on splash detachment and transport. Journal of Soil Science $32(2), 215-224$.

Ramos, M., Martínez-Casasnovas, J., 2006. Nutrient losses by runoff in vineyards of the Mediterranean Alt Penedès region (NE Spain). Agriculture, ecosystems \& environment 113 (1), 356-363.

Renard, K. G., Foster, G. R., Weesies, G. A., McCool, D., Yoder, D., et al., 1997. Predicting soil erosion by water: a guide to conservation planning with the revised universal soil loss equation (RUSLE). Vol. 703 of Agriculture Handbook. Washington, US Government Printing Office.

Ritchie, J. C., McCarty, G. W., Venteris, E. R., Kaspar, T., 2007. Soil and soil organic carbon redistribution on the landscape. Geomorphology 89, 163-171.

Rose, C., 1960. Soil detachment caused by rainfall. Soil Science 89 (1), 28-35.

Rouder, J., Morey, R., 2013. Default Bayes factors for model selection in regression). Multivariate Behavioral Research 47, 877-903.

Rouder, J. N., Morey, R. D., 2012. Default bayes factors for model selection in regression. Multivariate Behavioral Research 47 (6), 877-903. 
Sinoga, J. D. R., Pariente, S., Díaz, A. R., Murillo, J. F. M., 2012. Variability of relationships between soil organic carbon and some soil properties in Mediterranean rangelands under different climatic conditions (South of Spain). Catena 94 (0), 17-25.

Strickland, T., Truman, C., Frauenfeld, B., 2005. Variable rainfall intensity effects on carbon characteristics of eroded sediments from two coastal plain ultisols in Georgia. Journal of soil and water conservation 60 (3), 142-147. 


\section{"Appendices}

611

612

\section{Appendix A. Laboratory analysis of the soils}

The properties of the three soils under study were determined based on one sample from the upper $20 \mathrm{~cm}$ for each soil. The samples were air-dried, grounded, homogenized and quartered to pass through a $2 \mathrm{~mm}$ sieve prior to the analysis.

The following properties were determined for each sample: i) bulk (considering the soil pores) and real (considering only the solid phase) density; ii) porosity; iii) fractions of sand (coarse sand: 250 to $2000 \mu \mathrm{m}$, medium sand: 100 to $250 \mu \mathrm{m}$, and fine sand: 50 to $100 \mu \mathrm{m}$ ), silt (50 to $2 \mu \mathrm{m}$ ) and clay $(<2 \mu \mathrm{m})$ particles and texture classification according to USDA (1973); iv) $\mathrm{pH}$; v) electric conductivity, EC; vi) cation exchange capacity, CEC; vii) organic matter; viii) $\mathrm{C}$ and $\mathrm{N}$ content, and $\mathrm{C} / \mathrm{N}$ ratio; ix) carbonates $\left(\mathrm{CO}_{3}\right)$ and gypsum $\left(\mathrm{CaSO}_{4} \cdot 2 \mathrm{H}_{2} \mathrm{O}\right)$ content.

Grain size was determined by a Coulter LS 230 equipment after chemical elimination of the organic matter.

The $\mathrm{pH}$ (1:2.5 soil:water) was measured using a $\mathrm{pH}$-meter.

EC was determined by a Crison 522 conductivimeter.

OM was determined by titration.

Carbonates were measured using a pressure calcimeter.

Total N was measured using the Kjeldhal Method.

CEC was determined by a $\mathrm{Mg}\left(\mathrm{NO}_{3}\right)_{2}$ solution followed by ICP-OES analysis. 
Table B.6: Pairwise model comparison for SOC concentration $\left(S O C_{c}\right)$ : Bayes factors of all possible comparisons between models, under the hypothesis that numerator $>$ denominator. The model configurations are: $\mathcal{M}_{0}$, null model (mean $S O C_{c}$ ); $\mathcal{M}_{1}, S O C_{c}$ as a function of soil type; $\mathcal{M}_{2}, S O C_{c}$ as a function of grain size fraction; $\mathcal{M}_{3}, S O C_{c}$ as a function of soil and fraction; and $\mathcal{M}_{4}, S O C_{c}$ as a function of soil, fraction, and their interaction. All five models include the event number as a random effect.

\begin{tabular}{|c|c|c|c|c|c|}
\hline numerator & $\begin{array}{c}\text { denominator } \\
\mathcal{M}_{0}\end{array}$ & $\mathcal{M}_{1}$ & $\mathcal{M}_{2}$ & $\mathcal{M}_{3}$ & $\mathcal{M}_{4}$ \\
\hline $\mathcal{M}_{0}$ & - & $2.77 \times 10^{-6}$ & $7.43 \times 10^{-14}$ & $6.82 \times 10^{-24}$ & $2.34 \times 10^{-26}$ \\
\hline $\mathcal{M}_{1}$ & $3.61 \times 10^{5}$ & - & $2.68 \times 10^{-8}$ & $2.46 \times 10^{-18}$ & $8.44 \times 10^{-21}$ \\
\hline $\mathcal{M}_{2}$ & $1.35 \times 10^{13}$ & $3.73 \times 10^{7}$ & - & $9.18 \times 10^{-11}$ & $3.15 \times 10^{-13}$ \\
\hline $\mathcal{M}_{3}$ & $1.47 \times 10^{23}$ & $4.06 \times 10^{17}$ & $1.09 \times 10^{10}$ & - & $3.00 \times 10^{-3}$ \\
\hline $\mathcal{M}_{4}$ & $4.28 \times 10^{25}$ & $1.18 \times 10^{20}$ & $3.18 \times 10^{12}$ & $2.92 \times 10^{2}$ & - \\
\hline
\end{tabular}

\section{Appendix B. Model comparison matrices}

Complete pairwise model comparison matrices of the models tested in the article. 
Table B.7: Pairwise model comparison for SOC concentration $\left(S O C_{c}\right)$ : Bayes factors of all possible comparisons between models, under the hypothesis that numerator $>$ denominator. The model configurations were: $\mathcal{M}_{4}, S O C_{c}$ as a function of soil, fraction, and their interaction; $\mathcal{M}_{5}, \mathcal{M}_{4}+\operatorname{splash} ; \mathcal{M}_{6}, \mathcal{M}_{4}+$ ei30; $\mathcal{M}_{7}, \mathcal{M}_{4}+$ splash + ei30; $\mathcal{M}_{8}, \mathcal{M}_{4}+$ splash + ei30 and their interaction. All five models included the event number as a random effect.

\begin{tabular}{cccccc}
\hline \multicolumn{3}{c}{ denominator } & & & \\
numerator & $\mathcal{M}_{4}$ & $\mathcal{M}_{5}$ & $\mathcal{M}_{6}$ & $\mathcal{M}_{7}$ & $\mathcal{M}_{8}$ \\
\hline $\mathcal{M}_{4}$ & - & $9.2 \times 10^{-1}$ & 1.53 & 1.37 & 3.99 \\
$\mathcal{M}_{5}$ & 1.09 & - & 1.66 & 1.49 & 4.33 \\
$\mathcal{M}_{6}$ & $6.55 \times 10^{-1}$ & $6.02 \times 10^{-1}$ & - & $8.95 \times 10^{-1}$ & 2.61 \\
$\mathcal{M}_{7}$ & $7.32 \times 10^{-1}$ & $6.73 \times 10^{-1}$ & 1.12 & - & 2.92 \\
$\mathcal{M}_{8}$ & $2.51 \times 10^{-1}$ & $2.31 \times 10^{-1}$ & $3.83 \times 10^{-1}$ & $3.43 \times 10^{-1}$ & - \\
\hline
\end{tabular}

Table B.8: Pairwise model comparison for SOC concentration $\left(S O C_{c}\right)$ : Bayes factors of all possible comparisons between models, under the hypothesis that numerator $>$ denominator. The model configurations are: $\mathcal{M}_{4}, S O C_{c}$ as a function of soil, fraction, and their interaction; $\mathcal{M}_{9}, \mathcal{M}_{4}+$ control; $\mathcal{M}_{10}, \mathcal{M}_{4}$ plus control and the interaction between control and soil type. All models include the event number as a random effect.

\begin{tabular}{cccccc}
\hline & denominator & & & & \\
numerator & $\mathcal{M}_{4}$ & $\mathcal{M}_{9}$ & $\mathcal{M}_{10}$ & $\mathcal{M}_{11}$ & $\mathcal{M}_{12}$ \\
\hline $\mathcal{M}_{4}$ & - & 1.23 & $1.23 \times 10^{-4}$ & $2.91 \times 10^{-1}$ & $1.93 \times 10^{-5}$ \\
$\mathcal{M}_{9}$ & $8.13 \times 10^{-1}$ & - & $9.99 \times 10^{-5}$ & $2.36 \times 10^{-1}$ & $1.57 \times 10^{-5}$ \\
$\mathcal{M}_{10}$ & $8.14 \times 10^{3}$ & $1.00 \times 10^{4}$ & - & $2.37 \times 10^{3}$ & $1.57 \times 10^{-1}$ \\
$\mathcal{M}_{11}$ & 3.44 & 4.23 & $4.23 \times 10^{-4}$ & - & $6.63 \times 10^{-5}$ \\
$\mathcal{M}_{12}$ & $5.19 \times 10^{4}$ & $6.39 \times 10^{4}$ & 6.38 & $1.51 \times 10^{4}$ & - \\
\hline
\end{tabular}


